\title{
PhaP phasins play a principal role in poly- $\beta$-hydroxybutyrate accumulation in free-living Bradyrhizobium japonicum
}

\author{
Ken-ichi Yoshida ${ }^{1,2^{*}}$, Yuki Takemoto ${ }^{1}$, Takayuki Sotsuka', Kosei Tanaka ${ }^{2}$ and Shinji Takenaka ${ }^{1,2}$
}

\begin{abstract}
Background: Bradyrhizobium japonicum USDA110, a soybean symbiont, is capable of accumulating a large amount of poly- $\beta$-hydroxybutyrate (PHB) as an intracellular carbon storage polymer during free-living growth. Within the genome of USDA110, there are a number of genes annotated as paralogs of proteins involved in PHB metabolism, including its biosynthesis, degradation, and stabilization of its granules. They include two phbA paralogs encoding 3-ketoacyl-CoA thiolase, two phbB paralogs encoding acetoacetylCoA reductase, five phbC paralogs encoding PHB synthase, two phaZ paralogs encoding PHB depolymerase, at least four phaP phasin paralogs for stabilization of PHB granules, and one phaR encoding a putative transcriptional repressor to control phaP expression.

Results: Quantitative reverse-transcriptase PCR analyses of RNA samples prepared from cells grown using three different media revealed that PHB accumulation was related neither to redundancy nor expression levels of the phbA, phbB, phbC, and phaZ paralogs for PHB-synthesis and degradation. On the other hand, at least three of the phaP paralogs, involved in the growth and stabilization of PHB granules, were induced under PHB accumulating conditions. Moreover, the most prominently induced phasin exhibited the highest affinity to PHB in vitro; it was able to displace PhaR previously bound to PHB.
\end{abstract}

Conclusions: These results suggest that PHB accumulation in free-living B. japonicum USDA110 may not be achieved by controlling production and degradation of PHB. In contrast, it is achieved by stabilizing granules autonomously produced in an environment of excess carbon sources together with restricted nitrogen sources.

Keywords: Bradyrhizobium japonicum, Phasin, PHB

\section{Background}

Poly- $\beta$-hydroxybutyrate (PHB) is a polymer used for the storage of carbon and energy in a large variety of prokaryotes. It is accumulated in the cytoplasm if a carbon source is provided in excess and if any other essential nutrient is limited [1]. PHB belongs to the polyesters class of polymers, which is of interest as an industrial plastic because of its biodegradability and origin from renewable resources. Microbial PHB synthesis is a promising strategy for the production of bioplastics and offers a promising opportunity to transition toward a futureoriented bioeconomy [2].

\footnotetext{
* Correspondence: kenyoshi@kobe-u.ac.jp

'Department of Agrobioscience, Graduate School of Agricultural Science, Kobe University, 1-1 Rokkodai, Nada, Kobe 657 8501, Japan

${ }^{2}$ Organization of Advanced Science and Technology, Kobe University, 1-1 Rokkodai, Nada, Kobe 657 8501, Japan
}

Most species of rhizobia synthesize PHB and accumulate it in intracellular granules [3]. In some species, PHB accumulation can exceed $50 \%$ of the cell's dry weight [4,5]. Various ways that rhizobia can use PHB to benefit their plant hosts have been proposed. For instance, it was proposed that PHB utilization could sustain the oxygen demand of the bacteroids during darkness; thus, contributing to the preservation of nodule activity and the continuation of nitrogen fixation at high rates [6]. PHB may also fuel the differentiation of rhizobia into nitrogen-fixing bacteroids [7]. In addition, rhizobia may simply degrade PHB in ways that enhance their own fitness. PHB may provide the energy and carbon required for bacterial reproduction, or for stress tolerance required within senescing nodules or after symbiotic rhizobia escape into the soil and transition to the freeliving state.

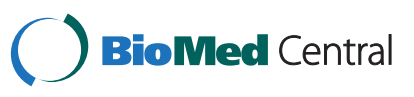

c) 2013 Yoshida et al.; licensee BioMed Central Ltd. This is an open access article distributed under the terms of the Creative Commons Attribution License (http://creativecommons.org/licenses/by/2.0), which permits unrestricted use, distribution, and reproduction in any medium, provided the original work is properly cited. 
Biochemically, PHB synthesis can compete with nitrogen fixation [1]. In addition, a negative correlation was observed between the rate of nitrogen fixation and $\mathrm{PHB}$ accumulation $[8,9]$. A mutant of Rhizobium etli, that did not accumulate $\mathrm{PHB}$, was shown to significantly fix more nitrogen than the isogenic wild type [10,11], whereas non-fixing nifH mutants of $R$. etli [12] and Bradyrhizobium japonicum [13] accumulated more PHB than their isogenic nitrogen-fixing parental strains. There is a conflict between rhizobia and legumes over the rate of PHB accumulation, due to the metabolic tradeoff between nitrogen fixation and PHB accumulation. Therefore, PHB biosynthesis and accumulation in species of rhizobia may be controlled to balance the tradeoff, but the mechanism underlying this control has not yet been fully explained.

One of the best studied microorganisms with respect to PHB biosynthesis and accumulation is the Gramnegative bacterium Ralstonia eutropha [14]. It synthesizes PHB using the three PHB synthetic genes: $p h b A$, which encodes 3-ketoacyl-CoA thiolase; $p h b B$, which encodes acetoacetyl CoA reductase; and $p h b C$, which encodes the enzyme PHB synthase. PHB degradation, however, is performed by $\mathrm{PHB}$ depolymerase, which is encoded by phaZ. Phasins, encoded by phaP, are a class of low-molecular-mass amphipathic proteins that form a layer at the surface of the PHB granule and stabilize it [15]. The $R$. eutropha possesses at least four phaP paralogs identified so far [16]. Expression of the major phasin, encoded by phaP1, is regulated by the transcriptional repressor PhaR $[17,18]$. Under conditions less favorable for PHB biosynthesis, PhaR binds to the phaP1 promoter region to repress transcription of this gene. After the onset of PHB biosynthesis, when the nascent PHB granules gradually form, PhaR leaves the promoter and binds to the granules so that phaP1 is transcribed and translated. During the later stages of PHB accumulation, PhaR is estimated to bind no longer to the granules as it is displaced by PhaP1 phasin. The displaced PhaR returns to bind to the phaP1 promoter and represses transcription again [16].

Most members of the Rhizobiaceae are known to possess single copies of the PHB biosynthesis genes. For instance, strains of Sinorhizobium meliloti, the symbionts of alfalfa, regarded as one of the model organisms to study symbiotic nitrogen fixation, are characterized to have a single set of the genes for PHB metabolism, namely $p h b A$, phbB, phbC, and phaZ [19,20], whereas two paralogous genes, phaP1 and phaP2, encode functional phasins [21]. On the other hand, strains of $B$. japonicum, the symbionts of soybean, are known to accumulate a large amount of PHB [22], and the B. japonicum USDA110 genome was found to contain five paralogs of $p h b C$, as well as two paralogs of $p h b A B$ [23].
This genetic redundancy may suggest a functional importance that has not yet been fully elucidated. In this study, we examined the expression profiles of the paralogs relevant to $\mathrm{PHB}$ metabolism in free-living B. japonicum cells under PHB accumulating and non-accumulating conditions. Then, we identified the phasin-encoding paralogs from the genomic information [24], and used a variety of tools to investigate their involvement in PHB accumulation.

\section{Results and discussion}

\section{$B$. japonicum candidate genes involved in metabolism} and $\mathrm{PHB}$ accumulation

The genome of $B$. japonicum USDA110 possesses five paralogs of $p h b C$, namely $p h b C 1$ (open reading frame blr2885), phbC2 (blr3732), phbC3 (bll4360), phbC4 (bll4548), and phbC5 (bll6073), as well as two paralogs of $p h b A$ and phbB, phbA1 (blr3724), phbA2 (bll0226), phbB1 (bll3725), and phbB2 (bll0225) [23]. We predicted that two putative phaZ genes from the $B$. japonicum genome [24] encode PHB depolymerases based on their similarities to the phaZ of S. meliloti (SMc02770 in S. meliloti 1021 genome) [25], which had previously been functionally characterized [20]. The results of amino acid sequence comparisons among the products of the $p h b C$ and $p h a Z$ paralogs are summarized in Figure 1. The gene products of $p h b C 2, p h b C 3$, and phbC5 are remarkably similar to each other. Those of phbC1 and phbC4are shorter but share similarities in the C-terminal regions of $p h b C 2$, phbC3, and phbC5. The phaZ paralogs were found to share weak similarities to $p h b C 1$, phbC4, and phbC5, which may have implications in the enzyme evolution for the reversal reactions of PHB polymerization and depolymerization.

Within the $B$. japonicum USDA110 genome, there are seven genes predicted to encode phasins because their deduced amino acid sequences could contain the Phasin_2 motif (http://pfam.sanger.ac.uk/family/PF09361) [27]. Judging from conservation of the motif, we selected four out of the seven genes for this study: phaP1 (bll5155), phaP2 (bll5555), phaP3 (bll6129), and phaP4 (bll7395). The motifs predicted in the other three putative phasin paralogs were assessed as less reliable (data not shown). These four paralogs are small proteins of 112-161 amino acid residues; an alignment of their amino acid sequences is shown in Figure 2. The putative phaR (blr0227), encoding the transcriptional repressor of phaP, was deduced by its similarity to the previously identified phaR of S. meliloti [21].

\section{Expression profile of the candidate genes in free-living cells}

Cells of B. japonicum USDA110 were inoculated into three different media [TY (tryptone yeast), PSY (peptone 


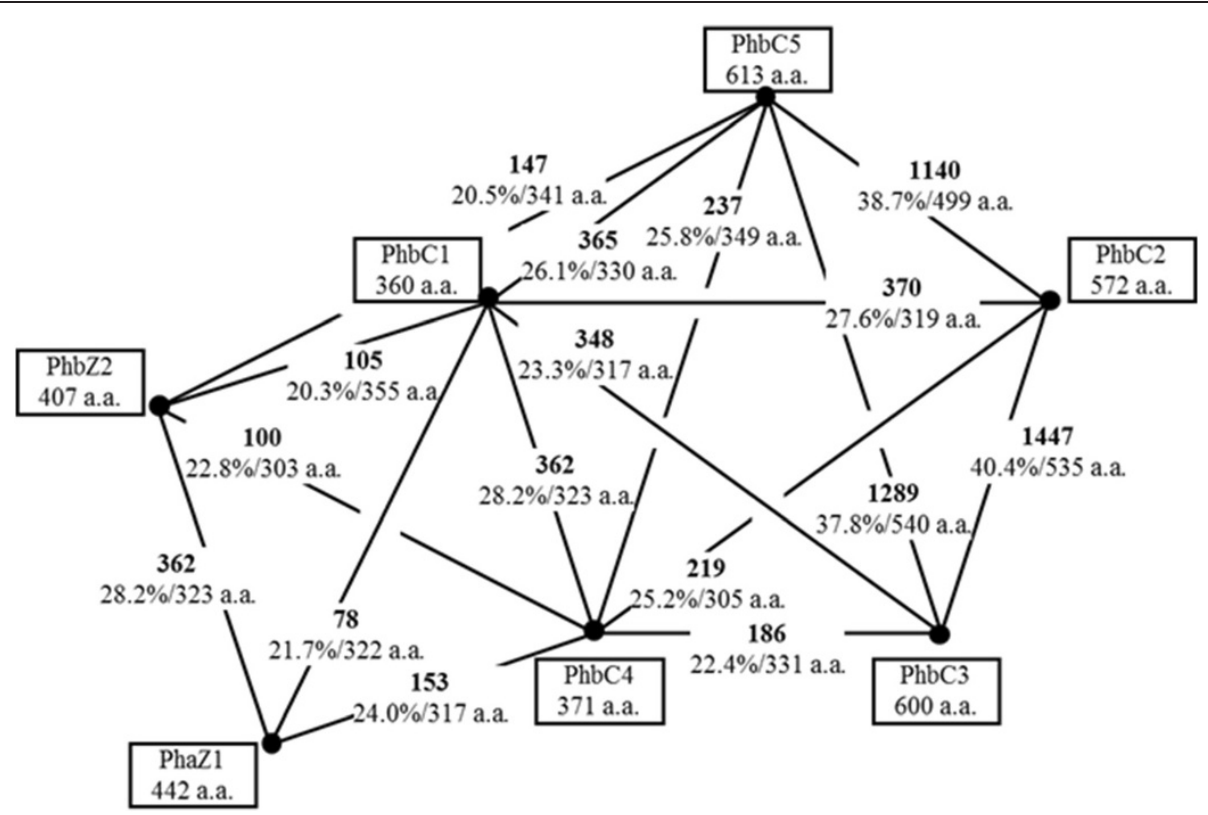

Figure 1 Similarities among the gene products putatively involved in PHB polymerization/depolymerization. Similarities were calculated using the FASTA program [26] for each of the indicated pairs. FASTA optimized scores (boldface) and sequence identity (percentage/overlapping amino acid residues) are shown. Size, given as the number of amino acid residues, is indicated beneath the product name.

salts yeast), and YEM (yeast extract mannitol)] and allowed to grow for eight days (Figure 3A). Cells exhibited the slowest growth in YEM, which is rich in carbon sources but poor in nitrogen sources. When the optical density reached 0.8 at $600 \mathrm{~nm}$, cells were harvested, and their intracellular PHB content was measured (Figure $3 \mathrm{~B}$ ). No PHB was detected in the cells grown in TY medium, whereas only a trace of PHB was detected in cells grown in PSY. On the other hand, a substantial amount of PHB was detected in the cells grown in YEM. Replacing mannitol, the carbon source in YEM, with an equivalent concentration of other sugars, including arabinose, mannose, glucose, and sorbitol, resulted in similar levels of PHB accumulation (data not shown). These results suggest that the PHB accumulation does not specifically depend on mannitol, but on the richness of the carbon sources together with a relative lack of nitrogen sources available in the medium. Under nutritional conditions in which carbon sources are in excess relative to nitrogen sources, the intracellular pool of substrates for PHB synthesis, including acetyl CoA and acetate, would be enlarged by less efficient nitrogen assimilation, which may be one of the signals triggering PHB accumulation.

PHB began to appear in cells cultured in YEM at an optical density of 0.6 at $600 \mathrm{~nm}$ (data not shown). We prepared total RNA samples from cells grown in each of the three media, and then subjected the samples to quantitative reverse transcriptase PCR (qRT-PCR)

\begin{tabular}{|c|c|}
\hline $\begin{array}{l}\text { phap2 (b115155) } \\
\text { phap2 (b115555) } \\
\text { phap3 (b116129) } \\
\text { phap4 (b117395) }\end{array}$ & 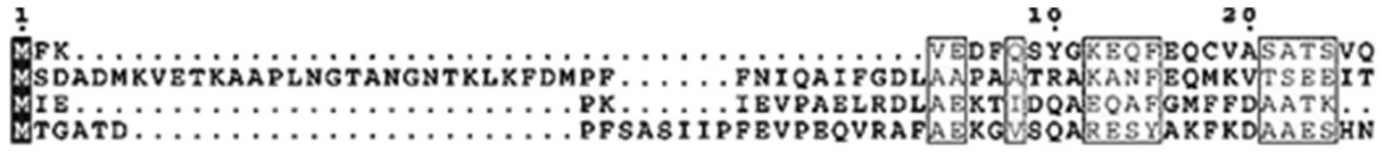 \\
\hline $\begin{array}{l}\text { phap2 (b125155) } \\
\text { phap2 (b115555) } \\
\text { phap3 (b116129) } \\
\text { phap4 (b127395) }\end{array}$ & 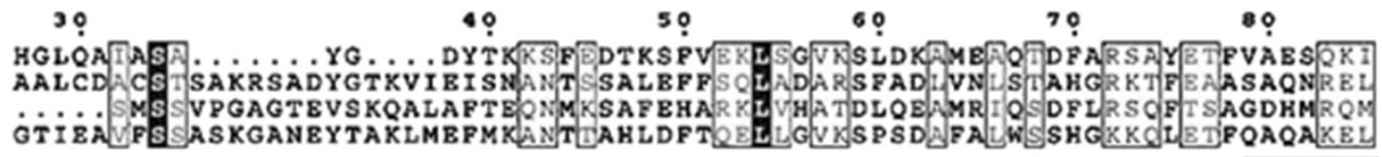 \\
\hline $\begin{array}{l}\text { phap1 (b115155) } \\
\text { phap2 (b115555) } \\
\text { phap3 (b116129) } \\
\text { phap4 (b117395) }\end{array}$ & 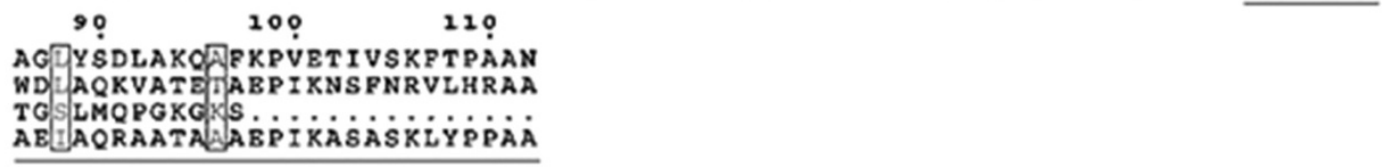 \\
\hline
\end{tabular}



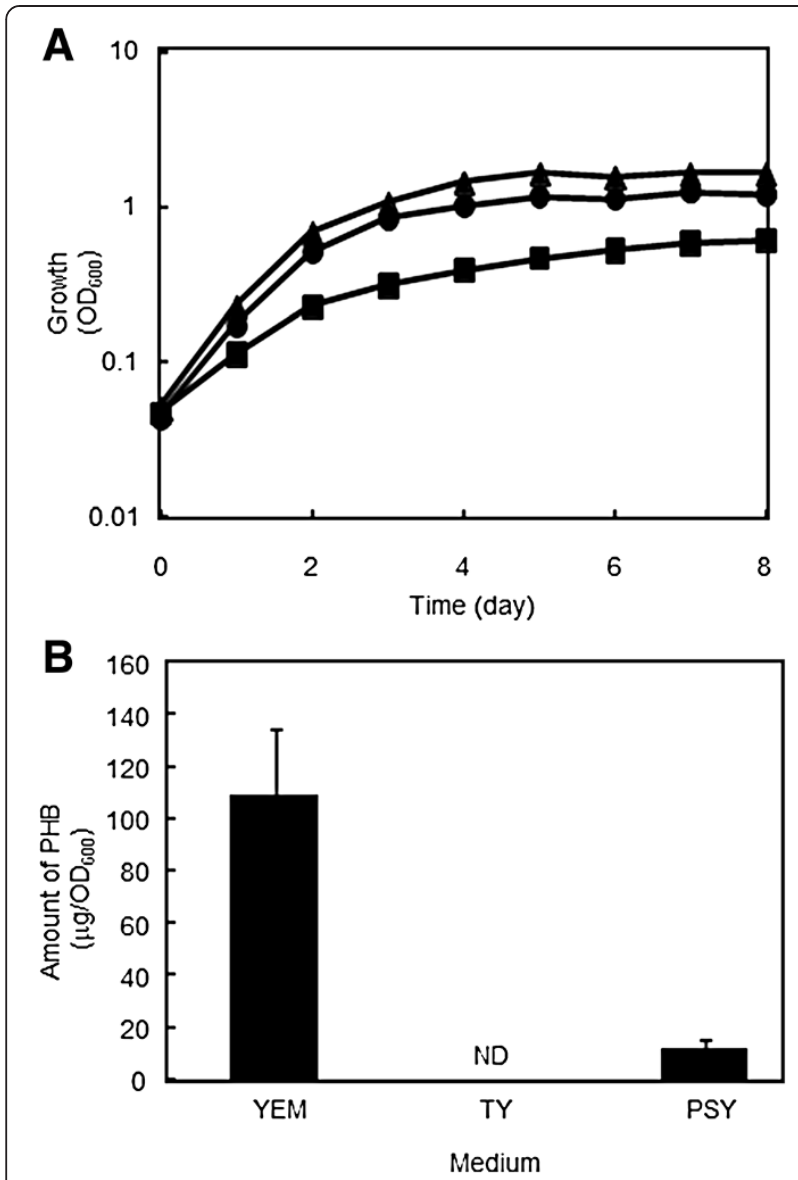

Figure 3 Growth and PHB accumulation of B. japonicum USDA110. (A) Growth curves for B. japonicum USDA110 cells grown in YEM (solid squares), TY (solid circles), and PSY (solid triangles) media. (B) Amounts of PHB accumulated. Values are means of three independent results \pm SD. ND: not detected.

analysis to measure the expression levels of the genes possibly involved in PHB biosynthesis and degradation. Among the genes predicted to be involved in $\mathrm{PHB}$ metabolism, we detected transcription of $p h b A 2$, phbB2, phbC3, phbC5, and phaZ1, whereas expression of the others was negligible (Figure 4A), indicating that only one or two of the respective paralogs functioned. Moreover, the levels of transcription of the PHB biosynthetic genes were higher under PHB non-accumulating conditions in TY medium than accumulating conditions in YEM, and thus obviously they were not induced upon PHB accumulation. It was also paradoxical that phaZ1, which could be involved in PHB degradation, seemed to be induced under PHB-accumulating conditions.

The transcription profile of phaP and phaR involved in PHB accumulation was also examined using qRTPCR (Figure 4B). In contrast to the PHB-metabolic genes, induction of some of the phaP encoding putative phasins correlated with $\mathrm{PHB}$ accumulation. Among the four phaP, phaP4 was most prominently induced under
PHB-accumulating conditions in YEM medium reaching levels up to 40 times greater than that of the control, sigA, which encodes the house-keeping sigma factor. These results imply that phaP4 may play an important role in PHB accumulation. When cultured in YEM, phaP1 and phaP2 were induced to levels up to 10 times greater than the control, implying that phaP1 and phaP2 may also have roles in PHB accumulation. In PSY medium, both phaP1 and phaP4 were induced to lower levels, which may be relevant to the lower PHB accumulation seen in this medium (Figure 3B). On the other hand, expression of phaR was kept at a low level and only barely enhanced upon PHB accumulation, which is consistent with the self-regulation model proposed in R. eutropha [16]. Transcription of phaP3 was almost constant and as low as that of phaR, and thus this paralog might be irrelevant to PHB accumulation under these conditions.

When all these results are considered, it is conceivable that PHB accumulation in B. japonicum during freeliving growth may not depend on either the redundancy or expression levels of the genes for PHB synthesis and degradation. Instead, it seems probable that the major mechanism allowing $B$. japonicum to accumulate large amounts of PHB may be the formation of PHB granules stabilized by phasins.

\section{The four PhaP phasins and PhaR bound to PHB with different affinities}

phaP1, phaP2, phaP3, phaP4, and phaR were cloned individually into Escherichia coli and expressed as $\mathrm{N}$-terminally $\mathrm{His}_{6}$-tagged fusion proteins. For unknown reason, the $\mathrm{His}_{6}$-tag fusions could not be purified by the conventional affinity chromatography. Therefore, the crude extracts of $E$. coli cells containing the fusions were used directly in the PHB binding experiment. Because the N-terminus of each fusion protein contained the same single $\mathrm{His}_{6}$-tag, we assumed that each $\mathrm{His}_{6}$-tag equally reacts with the anti- $\mathrm{His}_{6}$-tag antibody, presumably regardless of fusion partner, and the signal intensities on immunoblots probed for the $\mathrm{His}_{6}$-tag were used to represent the amounts of the phasin fusions contained in the extracts.

The crude extracts containing phasin and PhaR fusions, adequately diluted and controlled to give almost the same signal intensities on immunoblots, were mixed with a serially diluted suspension of fine PHB powder in test tubes, and incubated on ice to allow formation of $\mathrm{PHB} /$ protein complexes. The insoluble $\mathrm{PHB} /$ protein complexes were spun down, washed to remove out nonspecific proteins, and then subjected to SDS-PAGE followed by immunoblot analysis. As shown in Figure 5, all four phasin fusions, as well as the PhaR fusion, exhibited some PHB binding. This suggests that their native 

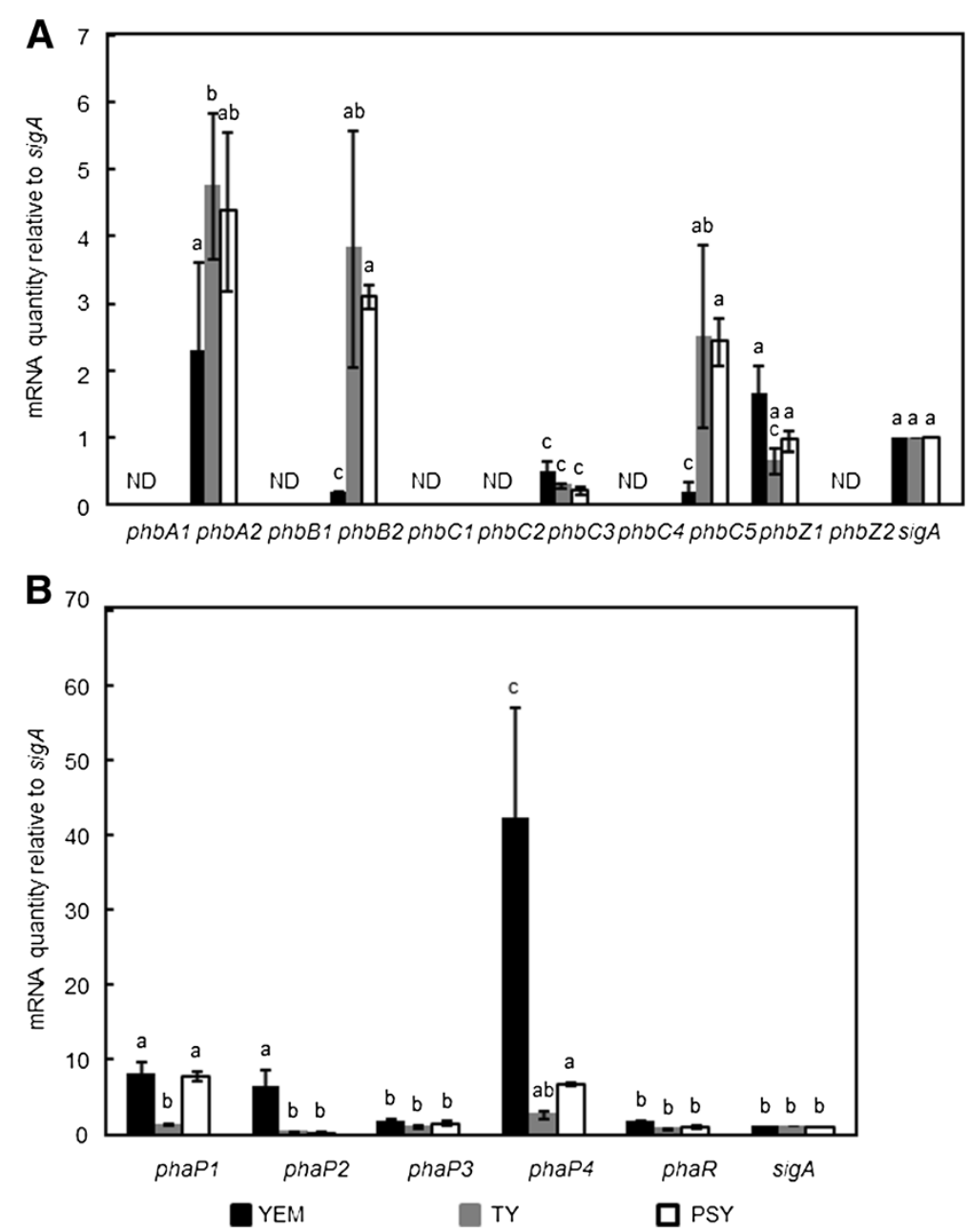

Figure 4 Transcription profile of the genes deduced to be involved in PHB metabolism and accumulation. (A) Expression of the genes for PHB biosynthesis and degradation. GRT-PCR analysis was performed as described in the Methods, and data were normalized to constitutively expressed sigA as an internal control. Values are means of three independent results \pm SD, and those followed by the same letters are not significantly different at the $95 \%$ confidence level. ND: no specific PCR product was detected as in the negative control experiment without reverse transcription, and thus was not taken into account for statistic analysis. (B) Expression of the four PhaP phasins. QRT-PCR analysis was performed and the results are presented as described for (A).

forms may possess the proposed function of covering the surface of PHB granules in vivo. PhaP4 and PhaR showed the highest affinities to PHB, as they bound it tightly at lower concentrations, whereas the other three had lower affinities. As mentioned above, these four PhaP proteins contain the Phasin_2 motif (http://pfam. sanger.ac.uk/family/PF09361), but only PhaP4 possesses the C-terminal region containing an amino acid sequence stretch very rich in alanine, in which 13 out of 34 residues are alanine (Figure 2). The alanine-rich sequence in the PhaP proteins of $R$. eutropha [28] was proposed to be important for exerting phasin function. This may also be the case with PhaP4 of B. japonicum.

Pötter and colleagues proposed the following mechanism for PHB granule development in R. eutropha [16]. When PHB is not produced, PhaR exerts its repressor function by binding DNA and repressing transcription of phaP1, which encodes the major phasin. With the onset of PHB accumulation, PhaR leaves the DNA to bind to the neonate $\mathrm{PHB}$ droplet, allowing induction of phaP1. Then, as more PhaP1 is produced and begins to occupy the surface of the growing PHB granule, PhaR is outcompeted and expelled from the granule and returns to DNA to repress phaP1 again. In order to determine if this proposed mechanism is also operating in B. japonicum, we compared the PHB affinities of PhaP4 and PhaR using an in vitro competition assay. Fixed amounts of PhaR and PHB were mixed in test tubes, and various amounts of PhaP4 were added to the mixture. After incubation, the proteins contained in the insoluble PHB/ protein complexes were subjected to the immunoblot analysis described above. As shown in Figure 6, as the 

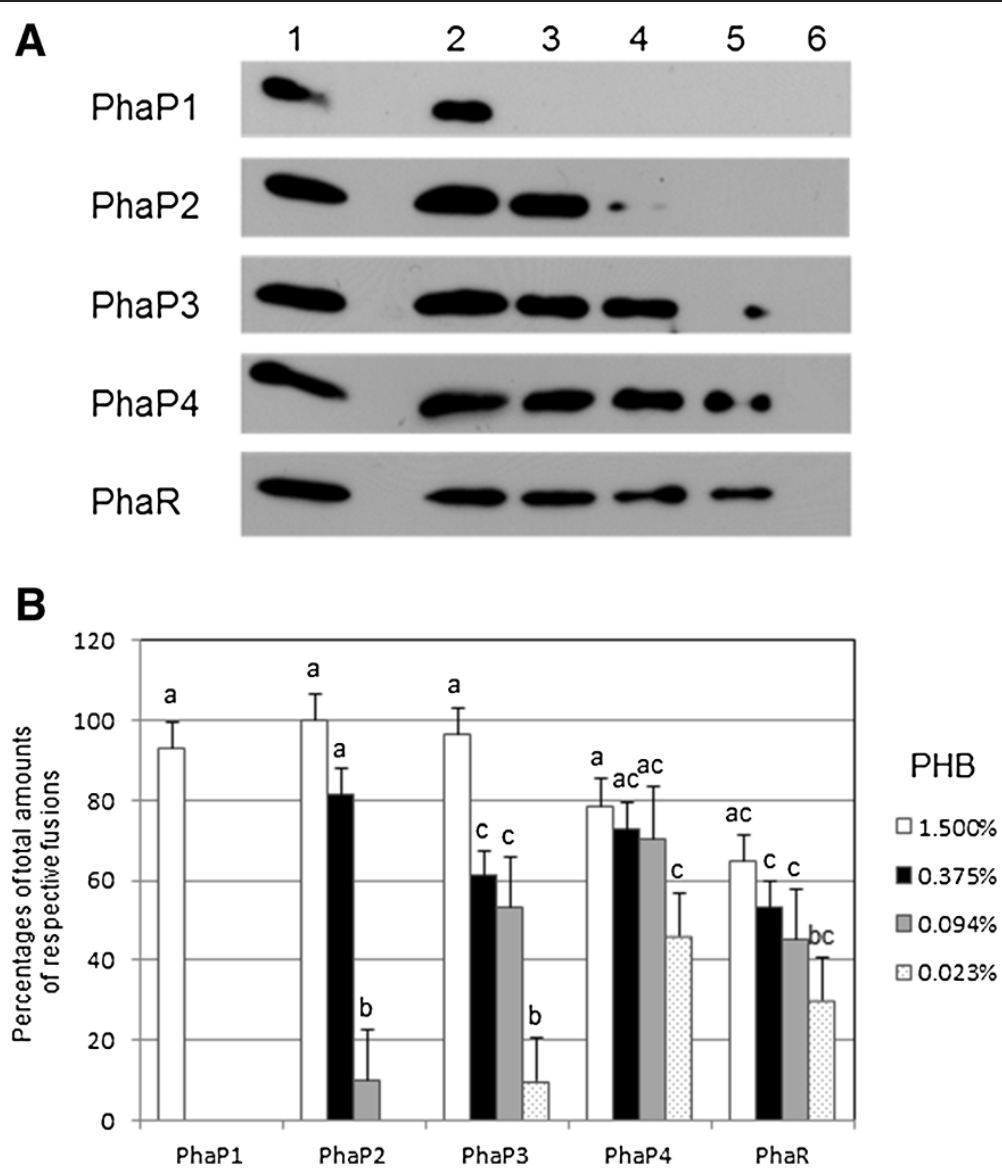

Figure 5 PHB binding of His $_{6}$-tag PhaP phasins and His $_{6}$-tag PhaR in vitro. (A) Immunoblots to detect proteins contained in PHB/protein complexes. The amounts of target protein in the crude extracts were compared to controls, and then fixed to contain the same concentration of each of the His $\sigma_{6}$ tag fusions of four PhaP phasins and PhaR. Target proteins were mixed with serially diluted suspensions of PHB, as a fine powder, in test tubes and incubated to allow formation of PHB/protein complexes. The PHB/protein complexes were spun down, washed to remove non-specific proteins, and then subjected to 18\% SDS-PAGE followed by the immunoblot analysis as described in the Methods. Total crude extract in a tube (lane 1) and proteins contained in the PHB/protein complexes formed without (lane 6) and with 1.500\% (w/v) (lane 2), 0.375\% (lane 3), 0.094\% (lane 4), and 0.023\% (lane 5) PHB are loaded. One set of representative data, from three independent experiments with similar results, is shown. (B) Summary of PHB binding assay. Signal intensities on the immunoblots were quantified using ImageJ software [29] and defined as the parameters representing the amounts of the $\mathrm{His}_{6}$-tag fusion proteins on the blots. The amounts of His 6 -tag fusions contained in the PHB/protein complexes, formed without (lane 6 in panel A) and with 1.500\% (w/v) (lane 2), 0.375\% (lane 3), 0.094\% (lane 4), and 0.023\% (lane 5) PHB, are expressed as percentages of total amounts of respective fusions (lane 1). Values are means of three independent results \pm SD, and those followed by the same letters are not significantly different at the $95 \%$ confidence level.

amount of PhaP4 increased, more PhaP4 and less PhaR were found in the complexes. These results indicate that PhaP4 and PhaR competed with each other for binding to $\mathrm{PHB}$, and that PhaP4 at higher concentrations could replace PhaR bound to PHB. We have already shown, above, that phaP4 was most prominently induced upon PHB accumulation (Figure 4B). Taken together, the results obtained in this study suggest that PhaP4 may play the most important role among the four PHB-binding phasins, and could possibly be regulated by PhaR using a mechanism similar to the one proposed in R. eutropha.

We have not experimentally assessed the actual repressor function of PhaR; these experiments will be performed and reported later. In addition, to confirm the importance of phaP4 and phaR, we attempted to construct knockout of these, as well as the other phaP. However, for unknown reasons, repeated attempts were not successful. We have considered the construction of $B$. japonicum mutants overexpressing these genes to see the effects not only during free-living growth but also during symbiosis with the host plant. The results of these experiments would be reported in the near future.

\section{Conclusions}

B. japonicum USDA110 accumulated intracellular PHB during free-living culture in the presence of excess carbon sources together with restricted nitrogen sources. Its genome contains redundant paralogs that could be 


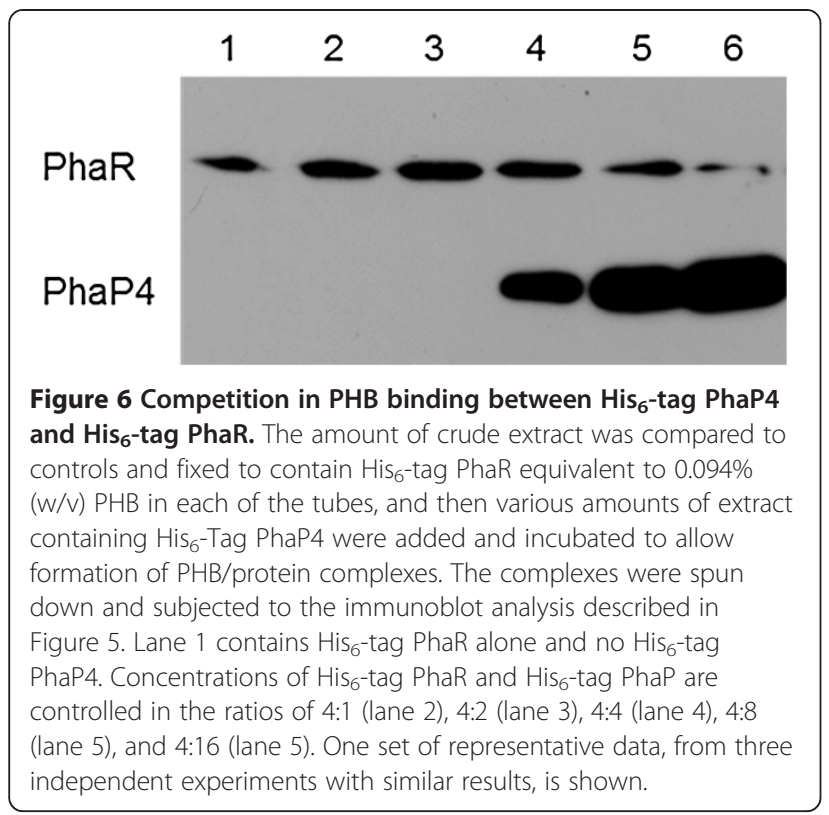

involved in PHB biosynthesis and degradation, but only one or two of each paralog family was found to be expressed during free-living growth. In addition, expression of the PHB metabolic genes was not correlated with PHB accumulation. Thus, it is conceivable that PHB accumulation during free-living growth is independent of redundancy or expression levels of PHB metabolic genes. Instead, it was found that some of the four phaP encoding phasins were induced upon PHB accumulation. All the four phasins exhibited some PHB binding in vitro. PhaP4 showed the highest affinity for PHB and could be responsible for the majority of PhaP function. Furthermore, PhaP4 was able to compete for PHB binding with PhaR, which is its plausible transcriptional repressor and possesses high affinity to PHB. PhaP4 is able to expel $\mathrm{PhaR}$ and stabilize the PHB granule. Therefore, in freeliving $B$. japonicum, carbon sources in excess relative to nitrogen sources enlarge the pool of substrates for PHB synthesis, such as acetyl-CoA and acetate. This could allow elevation in levels of intracellular PHB, which is recognized by PhaR repressor. This recognition triggers induction of phasins, including PhaP4 and maybe some others. Phasins then autonomously stabilize the accumulated PHB granules. This proposed mechanism resembles the mechanism proposed in R. eutropha.

\section{Methods}

Bacterial strains, plasmids, primers, and culture conditions

Bacterial strains and plasmids used in this study are listed in Table 1. A platinum loop full of glycerol frozen stock culture of B. japonicum USDA101 was used to inoculate PSY liquid medium [30] and allowed to grow for
Table 1 Bacterial strains and plasmids

\begin{tabular}{|c|c|c|}
\hline $\begin{array}{l}\text { Strains and } \\
\text { plasmids }\end{array}$ & Relevant genotypes and derivation & $\begin{array}{l}\text { Source and } \\
\text { reference }\end{array}$ \\
\hline \multicolumn{3}{|l|}{ B. japonicum } \\
\hline USDA110 & & 24 \\
\hline \multicolumn{3}{|l|}{ E. coli } \\
\hline DH5a & $\begin{array}{l}\text { supE44, DlacU169, hsdR17, recA1, } \\
\text { endA1, gyrA96, thi-1, relA1 }\end{array}$ & $\begin{array}{l}\text { Laboratory } \\
\text { stocks }\end{array}$ \\
\hline BL21 (DE3) & $F^{-}$ompT hsdS $\left(r_{\mathrm{b}}^{-} m_{\mathrm{b}}^{-}\right) g a l d c m(D E 3)$ & $\begin{array}{l}\text { Laboratory } \\
\text { stocks }\end{array}$ \\
\hline \multicolumn{3}{|l|}{ Plasmids } \\
\hline pET-28b & $\begin{array}{l}\text { Protein expression vector, } \\
\text { kanamycin resistant }\end{array}$ & Takara Bio \\
\hline pETPhaP1 & pET28b carrying phaP1 & This work \\
\hline pETPhaP2 & pET28b carrying phaP2 & This work \\
\hline pETPhaP3 & pET28b carrying phaP3 & This work \\
\hline pETPhaR & pET28b carrying phaR & This work \\
\hline pColdll & $\begin{array}{l}\text { Protein expression vector, } \\
\text { ampicillin resistant }\end{array}$ & Takara Bio \\
\hline pColdPhaP4 & pColdll carrying phaP4 & This work \\
\hline
\end{tabular}

five days at $28^{\circ} \mathrm{C}$ with shaking at $180 \mathrm{rpm}$. Aliquots of this culture were diluted with YEM [31], TY [19], or PSY media, to an optical density of 0.05 at $600 \mathrm{~nm}$. These three cultures were further incubated at $28^{\circ} \mathrm{C}$ with shaking at $180 \mathrm{rpm}$. Strains of $E$. coli were usually maintained at $37^{\circ} \mathrm{C}$ on LB plates with $50 \mu \mathrm{g} / \mathrm{mL}$ kanamycin or ampicillin added, as required.

\section{Quantification of PHB}

USDA101 cells in the cultures were harvested by centrifugation, washed once in $50 \mathrm{mM}$ Tris- $\mathrm{HCl}(\mathrm{pH}$ 8.0) containing $1 \mathrm{M} \mathrm{NaCl}$, and then suspended in $10 \mathrm{mM}$ Tris- $\mathrm{HCl}(\mathrm{pH}$ 8.0) containing $5 \mathrm{mM}$ 2-mercaptoethanol, $5 \mathrm{mM}$ ethylenediaminetetraacetic acid, $10 \%(\mathrm{w} / \mathrm{v})$ glycerol, and $0.02 \mathrm{mM}$ phenylmethylsulfonyl fluoride. The cells were subsequently disrupted by sonication in an ice bath. An aliquot $(0.1 \mathrm{~mL})$ of the solution was mixed with $1.2 \mathrm{~mL}$ of $5 \%(\mathrm{w} / \mathrm{v})$ sodium hypochlorite, and incubated at $37^{\circ} \mathrm{C}$ for $1 \mathrm{~h}$. After centrifugation, the pellet was successively washed with $1 \mathrm{~mL}$ aliquots of water, acetone, and $99.5 \%$ ethanol. PHB contained in the dried pellet was extracted three times with $0.1 \mathrm{~mL}$ of chloroform at $50^{\circ} \mathrm{C}$, and the chloroform extracts were combined in a tube $(0.3 \mathrm{~mL}$ in total). After evaporating the chloroform, the remaining substances were dissolved in $1 \mathrm{~mL}$ of concentrated $\mathrm{H}_{2} \mathrm{SO}_{4}$, and the absorbance of the solution was measured at $235 \mathrm{~nm}$. Various amounts of commercially available PHB solid powder (Sigma Aldrich, St. Louis, MO) were treated using the procedure described above to produce a standard curve, which was then used to quantify PHB according to the absorbance. 


\section{Plasmid construction and production of the recombinant proteins}

DNA fragments corresponding to the coding regions of phaP1, phaP2, phaP3, phaP4, and phaR, flanked by specific restriction sites, were amplified using PCR from chromosomal DNA of USDA101 using the primer pairs described in Table 2. The DNA fragments were trimmed with the appropriate restriction enzymes and ligated to similarly restricted plasmid vector pET-28b or pColdII, so that each of the coding regions was fused with a $\mathrm{His}_{6}$-tag at its $\mathrm{N}$-terminus. After confirming the correct cloning using DNA sequencing, each of the recombinant plasmids was introduced into E. coli BL21(DE3), which was allowed to grow in $\mathrm{LB}$ liquid medium at $37^{\circ} \mathrm{C}$. In the middle of logarithmic growth, the temperature was shifted to $15^{\circ} \mathrm{C} ; 30 \mathrm{~min}$ later, isopropyl $\beta$-D-1-thiogalactopyranoside was added to the culture, which was further incubated for $15 \mathrm{~h}$. The cells in the culture were harvested by centrifugation, washed once in $50 \mathrm{mM}$ potassium phosphate buffer ( $\mathrm{pH} 8.0), 20 \%(\mathrm{w} / \mathrm{v})$ glycerol, and $0.5 \mathrm{M} \mathrm{NaCl}$, and then suspended in the same solution to be disrupted by sonication in an ice bath. After centrifugation, the supernatant was used in further experiments as the crude extract containing the recombinant protein.

\section{RNA techniques}

Total RNA was extracted from USDA110 cells using TRIZOL RNA isolation reagents (Life Technologies, Carlsbad, CA), treated with DNase I (Roche diagnostics, Basel, Switzerland), and then purified using the RNeasy Mini Kit (Qiagen, Venlo, Netherlands). The qRT-PCR was performed as follows. An aliquot $(1 \mu \mathrm{g})$ of the total RNA sample was reverse transcribed using the ReverTra Ace qPCR RT Kit (Toyobo, Tokyo, Japan). The resulting cDNA (75 ng) was mixed with THUNDERBIRD SYBR qPCR Mix (Toyobo) and specific primer pairs (RTgene name-F/R listed in Table 2, e.g., RTphbA1-F and RTphbA1-R), and then analyzed using a Thermal Cycler Dice Real Time System MRQ (Takara Bio, Otsu, Japan) according to the suppliers' procedures.

\section{PHB binding assay and immunoblot analysis}

The crude extract containing the recombinant protein was adequately diluted and mixed with a suspension containing various amounts of crystalline PHB solid powder (Sigma Aldrich) in $10 \mathrm{mM}$ Tris-HCl (pH 7.5). The mixture was incubated on ice for $90 \mathrm{~min}$, and then centrifuged to pellet the $\mathrm{PHB} /$ protein complexes. After washing with $10 \mathrm{mM}$ Tris- $\mathrm{HCl}(\mathrm{pH} 7.5)$, the pellet was suspended in loading buffer and applied to an 18\% SDSPAGE gel. Proteins separated by electrophoresis were transferred onto a polyvinylidene fluoride membrane that was subsequently probed with an Anti-His6 (2)
Table 2 Oligonucleotide primers

\begin{tabular}{|c|c|}
\hline Oligonucleotide primers & $\begin{array}{l}\text { Sequence (designed restriction } \\
\text { sites are underlined) }\end{array}$ \\
\hline PhaP1 Ndel & 5'-GGAATTCCATATGATGTTCAAGGTTGAAGACTT-3' \\
\hline PhaP1 Xhol & 5'-CCGCTCGAGTAGTTGGCGGCCGGGGTGA-3' \\
\hline PhaP2 Ndel & 5'-GGAATTCCATATGGTGAGTGATGCCGATATGAA-3' \\
\hline PhaP2 Xhol & 5'-CCGCTCGAGTCAAGCAGCCCTATGCAGAA-3' \\
\hline PhaP3 Ndel & 5'-GGAATTCCATATGATGATCGAACCGAAAATCGA-3' \\
\hline PhaP3 Xhol & 5'-CCGCTCGAGTCAGGATTGGCCTTGCCCG-3' \\
\hline PhaP4 Ndel & 5'-GGAATTCCATATGATGACAGGTGCGACTGATCC-3' \\
\hline PhaP4 Hindlll & 5'-CCCAAGCTTTCAGGCGGCGGGCGGGTAGA-3' \\
\hline PhaR Ndel & 5'-GGAATTCCATATGGCGAAATCAGACCAACCCAC-3' \\
\hline PhaR Hindlll & 5'-CCCAAGCTTCTACTCTTCCTTCTTCGACA-3' \\
\hline RTphbA1-F & 5'-CATCGCCGTCAACAAGGA-3' \\
\hline RTphbA1-R & 5'-CCGCTTCTGCATCTCGAAC-3' \\
\hline RTphbA2-F & 5'-AAGAAGGCCGGCTGGAA-3' \\
\hline RTphbA2-R & 5'-CCATTGACGTTGACCTTGGA-3' \\
\hline RTphbB1-F & 5'-TCGAACTACGACGCCTGTG-3' \\
\hline RTphbB1-R & 5'-ATGCCGTCCTTGGTGATG-3' \\
\hline RTphbB2-F & 5'-CCGAAGGCGTGAAGAAGGT-3' \\
\hline RTphbB2-R & 5'-GAACAGCGAGCCGAGATTG-3' \\
\hline RTphbC1-F & 5'-GCTCTGGGAAAACATCTGGAAC-3' \\
\hline RTphbC1-R & 5'-TTGGTGATGGTGCGGAAA-3' \\
\hline RTphbC2-F & 5'-GGACGACTACGTTGAGGATGG-3' \\
\hline RTphbC2-R & 5'-AATGGCGAGTGCGGATG-3' \\
\hline RTphbC3-F & 5'-ATGACCGCGTCGAACCA-3' \\
\hline RTphbC3-R & 5'-GGCACCTTGACCTTGGAGA-3' \\
\hline RTphbC4-F & 5'-GGCGAAGACAGGCAAACA-3' \\
\hline RTphbC4-R & 5'-CTCCATCCATCCGAACCA-3' \\
\hline RTphbC5-F & 5'-CCGCAAAATTCCCTGGTC-3' \\
\hline RTphbC5-R & 5'-CATCCCTGTCCTTCGCATC-3' \\
\hline RTphaZ1-F & 5'-CCGAAGCAACGCACACA-3' \\
\hline RTphaZ1-R & 5'-ATCCTCGGCACGATTTCC-3' \\
\hline RTphaZ2-F & 5'-GGCACATCAAGCAGCACA-3' \\
\hline RTphaZ2-R & 5'-AGATCCATCACCGCGAAA-3' \\
\hline RTphaP1-F & 5'-ACGGCGACTACACCAAGAAG-3' \\
\hline RTphaP1-R & 5'-GAAGGTCTCGTAGGCGGAAC-3' \\
\hline RTphaP2-F & 5'-TCGCTITACCGAGCAGAAC-3' \\
\hline RTphaP2-R & 5'-GTGAACTGGCTACGCAGGA-3' \\
\hline RTphaP3-F & 5'-ATTACGGCACCAAGGTCATC-3' \\
\hline RTphaP3-R & 5'-GTGGAGAGGTTCACGAGGTC-3' \\
\hline RTphaP4-F & 5'-GTGCGACTGATCCATTCTCC-3' \\
\hline RTphaP4-R & 5'-GTCCTTGAACTTGGCGTAGC-3' \\
\hline RTphaR-F & 5'-CTTCGAGCAGGAGAACAAGG-3' \\
\hline RTphaR-R & 5'-GATATTTCGGCACCACCATC-3' \\
\hline RTsigA-F & 5'-CAGGCGAAGGACAAGGAAAA-3' \\
\hline RTsigA-R & 5'-CGTCGGACAGATCGAGCAA-3' \\
\hline
\end{tabular}


antibody (Roche) and goat anti-mouse IgM-HRP (Santa Cruz Biotech, Santa Cruz, CA), and visualized with ImmunoStar LD (Wako Pure Chemical Industries, Osaka, Japan).

\section{Statistical analysis}

Microsoft Excel Spreadsheet has been used for data processing. When needed, data were subjected to one-way analysis of variance followed by the Tukey-Kramer multiple comparison test.

\section{Abbreviations}

PHB: Poly- $\beta$-hydroxybutyrate; PSY: Peptone salts yeast; qRT-PCR: Quantitative reverse-transcriptase PCR; SDS-PAGE: SDS-polyacrylamide gel electrophoresis.

\section{Competing interests}

The authors declare that they have no competing interests.

\section{Authors' contributions}

Conception and design of the study: KY. Acquisition of data: YT and TS. Analysis and interpretation of data: $K T$. Drafting the article: KY. Revising it critically for important intellectual content: KT and ST. Final approval of the version to be submitted: All the co-authors. All authors read and approved the final manuscript.

\section{Acknowledgements}

The authors are grateful to Hisayuki Mitsui, Tohoku University, for providing B. japonicum USDA110, and to Akihiro Motokubota for his technical assistance. This work was financially supported by the Ministry of Education, Culture, Sports, Science and Technology, Japan: in part by Special Coordination Funds for Promoting Science and Technology, Creation of Innovative Centers for Advanced Interdisciplinary Research Areas; by the Advanced Low-Carbon Technology Research and Development Program; and by Grants-in-Aid from the NC-CARP project. The authors would like to thank Enago (www.enago.jp) for the English language review.

Received: 1 September 2013 Accepted: 9 December 2013 Published: 11 December 2013

\section{References}

1. Anderson AJ, Dawes EA: Occurrence, metabolism, metabolic role, and industrial uses of bacterial polyhydroxyalkanoates. Microbiol Rev 1990, 54:450-472.

2. Hamieh A, Olama Z, Holail H: Microbial production of polyhydroxybutyrate, a biodegradable plastic using agro-industrial waste products. Glo Adv Res J Microbiol 2013, 2:54-64.

3. Zevenhuizen LP: Cellular glycogen, beta-1,2-glucan, poly betahydroxybutyic acid and extracellular polysaccharides in fast-growing species of Rhizobium. Antonie Van Leeuwenhoek 1981, 47:481-497.

4. Bergersen FJ, Turner GL: Bacteroids from soybean root nodules: respiration and $\mathrm{N}_{2}$ fixation in flow-chamber reactions with oxyleghaemoglobin. Proc R Soc Lond B 1990, 238:295-320.

5. Tavernier P, Portais J, Nava S, Courtois J, Courtois B, Barbotin JN: Exopolysaccharide and poly-(beta)-hydroxybutyrate coproduction in two Rhizobium meliloti strains. Appl Environ Microbiol 1997, 63:21-26.

6. Bergersen FJ, Peoples MB, Turner GL: A role for poly- $\beta$ hydroxybutyrate in bacteroids of soybean nodules. Proc R Soc Lond B 1991, 245:59-64

7. Lodwig EM, Leonard M, Marroqui S, Wheeler TR, Findlay K, Downie JA, Poole PS: Role of polyhydroxybutyrate and glycogen as carbon storage compounds in pea and bean bacteroids. Mol Plant Microbe Interact 2005, 18:67-74.

8. Kretovich VL, Romanov VI, Yushkova LA, Shramko VI, Fedulova NG: Nitrogen fixation and poly- $\beta$-hydroxybutyric acid content in bacteroids of Rhizobium lupini and Rhizobium leguminosarum. Plant Soil 1977, 48:291-302.

9. Romanov VI, Fedulova NG, Tchermenskaya IE, Shramko VI, Molchanov MI, Kretovich WL: Metabolism of poly- $\beta$-hydroxybutyric acid in bacteroids of
Rhizobium lupini in connection with nitrogen fixation and photosynthesis. Plant Soil 1980, 56:379-390.

10. Cevallos MA, Encarnacion S, Leija A, Mora Y, Mora J: Genetic and physiological characterization of a Rhizobium etli mutant strain unable to synthesize poly-beta-hydroxybutyrate. J Bacterio/ 1996, 178:1646-1654.

11. Peralta H, Mora Y, Salazar E, Encarnacion S, Palacios R, Mora J: Engineering the nifH promoter region and abolishing poly- $\beta$-hydroxybutyrate accumulation in Rhizobium etli enhance nitrogen fixation in symbiosis with Phaseolus vulgaris. Appl Environ Microbiol 2004, 70:3272-3281.

12. Cermola M, Federova E, Tate R, Riccio A, Favre R, Patriarca EJ: Nodule invasion and symbiosome differentiation during Rhizobium etli-Phaseolus vulgaris symbiosis. Mol Plant Microbe Interact 2000, 13:733-741.

13. Hahn M, Studer D: Competitiveness of a nif- Bradyrhizobium japonicum mutant against the wild-type strain. FEMS Microbiol Lett 1986, 33:143-148

14. Steinbüchel A, Schlegel HG: Physiology and molecular genetics of poly ( $\beta$-hydroxy-alkanoic acid) synthesis in Alcaligenes eutrophus. Mol Microbiol 1991, 5:535-542.

15. Steinbüchel A, Aerts K, Babel W, Follner C, Liebergesell M, Madkour MH, Mayer F, Pieper-Furst U, Pries A, Valentin HE: Considerations on the structure and biochemistry of bacterial polyhydroxyalkanoic acid inclusions. Can J Microbiol 1995, 41:94-105.

16. Pötter $M$, Steinbüchel A: Poly(3-hydroxybutyrate) granule-associated proteins: impacts on poly(3-hydroxybutyrate) synthesis and degradation. Biomacromolecules 2005, 6:552-560.

17. Pötter M, Madkour MH, Mayer F, Steinbüchel A: Regulation of phasin expression and polyhydroxyalkanoate (PHA) granule formation in Ralstonia eutropha H16. Microbiology 2002, 148:2413-2426.

18. York G, Stubbe MJ, Sinskey AJ: The Ralstonia eutropha PhaR protein couples synthesis of the PhaP phasin to the presence of polyhydroxybutyrate in cells and promotes polyhydroxybutyrate production. J Bacterio/ 2002, 184:59-66.

19. Tombolini R, Povolo S, Buson A, Squartini A, Nuti MP: Poly-betahydroxybutyrate (PHB) biosynthetic genes in Rhizobium meliloti 41. Microbiology 1995, 141:2553-2559.

20. Trainer MA, Capstick D, Zachertowska A, Lam KN, Clark SR, Charles TC: Identification and characterization of the intracellular poly-3-hydroxybut yrate depolymerase enzyme PhaZ of Sinorhizobium meliloti. BMC Microbiol 2010, 10:92.

21. Wang C, Sheng X, Equi RC, Trainer MA, Charles TC, Sobral BWS: Influence of the poly-3-hydroxybutyrate (PHB) granule-associated proteins (PhaP1 and PhaP2) on PHB accumulation and symbiotic nitrogen fixation in Sinorhizobium meliloti Rm1021. J Bacteriol 2007, 189:9050-9056.

22. Klucas RV, Evans HJ: An electron donor system for nitrogenasedependent acetylene reduction by extracts of soybean nodules. Plant Physiol 1968, 43:1458-1460.

23. Aneja P, Dai M, Lacorre DA, Pillon B, Charles TC: Heterologous complementation of the exopolysaccharide synthesis and carbon utilization phenotypes of Sinorhizobium meliloti Rm1021 polyhydroxyalkanoate synthesis mutants. FEMS Microbiol Lett 2004 239:277-283.

24. Kaneko T, Nakamura Y, Sato S, Minamisawa K, Uchiumi T, Sasamoto S, Watanabe A, Idesawa K, Iriguchi M, Kawashima K, Kohara M, Matsumoto M, Shimpo S, Tsuruoka H, Wada T, Yamada M, Tabata S: Complete genomic sequence of nitrogen-fixing symbiotic bacterium Bradyrhizobium japonicum USDA110. DNA Res 2002, 9:189-197.

25. Galibert F, Finan TM, Long SR, Puhler A, Abola P, Ampe F, Barloy-Hubler F, Barnett MJ, Becker A, Boistard P, Bothe G, Boutry M, Bowser L, Buhrmester J, Cadieu E, Capela D, Chain P, Cowie A, Davis RW, Dreano S, Federspiel NA, Fisher RF, Gloux S, Godrie T, Goffeau A, Golding B, Gouzy J, Gurjal M, Hernandez-Lucas I, Hong A, et al: The composite genome of the legume symbiont Sinorhizobium meliloti. Science 2001, 293:668-672.

26. Pearson WR, Lipman DJ: Improved tools for biological sequence comparison. Proc Natl Acad Sci U S A 1988, 85:2444-2448.

27. Punta M, Coggill PC, Eberhardt RY, Mistry J, Tate J, Boursnell C, Pang N, Forslund K, Ceric G, Clements J, Heger A, Holm L, Sonnhammer ELL, Eddy SR, Bateman A, Finn RD: The Pfam protein families database. Nucleic Acids Res 2012, Database Issue 40:D290-D301.

28. Neumann L, Spinozzi F, Sinibaldi R, Rustichelli F, Pötter M, Steinbüchel A Binding of the major phasin, PhaP1, from Ralstonia eutropha $\mathrm{H} 16$ to poly (3-hydroxybutyrate) granules. J Bacteriol 2008, 190:2911-2919. 
29. Schneider CA, Rasband WS, Eliceiri KW: NIH Image to ImageJ: 25 years of image analysis. Nat Methods 2012, 9:671-675.

30. Regensburger B, Hennecke H: RNA polymerase from Rhizobium japonicum. Arch Microbiol 1983, 135:103-109.

31. Vincent JM: A Manual for the Practical Study of Root-Nodule Bacteria, International Biological Programme Handbook No. 15. Oxford, England: Blackwell Science Publications; 1970.

doi:10.1186/1471-2180-13-290

Cite this article as: Yoshida et al.: PhaP phasins play a principal role in poly- $\beta$-hydroxybutyrate accumulation in free-living Bradyrhizobium japonicum. BMC Microbiology 2013 13:290

\section{Submit your next manuscript to BioMed Central and take full advantage of:}

- Convenient online submission

- Thorough peer review

- No space constraints or color figure charges

- Immediate publication on acceptance

- Inclusion in PubMed, CAS, Scopus and Google Scholar

- Research which is freely available for redistribution 